\title{
IL4 gene polymorphism and previous malaria experiences manipulate anti-Plasmodium falciparum antibody isotype profiles in complicated and uncomplicated malaria
}

\author{
Piyatida Tangteerawatana1,2, Hedvig Perlmann³ , Masashi Hayano3 ${ }^{3}$ \\ Thareerat Kalambaheti ${ }^{1}$, Marita Troye-Blomberg ${ }^{3}$ and Srisin Khusmith*1
}

\begin{abstract}
Address: ${ }^{1}$ Department of Microbiology and Immunology, Faculty of Tropical Medicine, Mahidol University, 420/6 Rajvithi Road, Bangkok 10400 Thailand, ${ }^{2}$ Department of Microbiology, Faculty of Medicine, Srinakharinwirot University, Bangkok, Thailand and ${ }^{3}$ Department of Immunology, Wenner-Gren Institute, Stockholm University, Stockholm, Sweden

Email: Piyatida Tangteerawatana - piyatida@swu.ac.th; Hedvig Perlmann - hedvig.perlmann@imun.su.se; Masashi Hayano - masashi@imun.su.se; Thareerat Kalambaheti - tmtkl@mahidol.ac.th; Marita Troye-Blomberg - marita@imun.su.se; Srisin Khusmith* - tmskm@mahidol.ac.th

* Corresponding author
\end{abstract}

Published: 10 December 2009

Malaria Journal 2009, 8:286 doi:10.1186/1475-2875-8-286
Received: 19 July 2009

Accepted: 10 December 2009

This article is available from: http://www.malariajournal.com/content/8/I/286

(C) 2009 Tangteerawatana et al; licensee BioMed Central Ltd.

This is an Open Access article distributed under the terms of the Creative Commons Attribution License (http://creativecommons.org/licenses/by/2.0), which permits unrestricted use, distribution, and reproduction in any medium, provided the original work is properly cited.

\begin{abstract}
Background: The IL4-590 gene polymorphism has been shown to be associated with elevated levels of anti-Plasmodium falciparum IgG antibodies and parasite intensity in the malaria protected Fulani of West Africa. This study aimed to investigate the possible impact of IL4-590C/T polymorphism on anti-P. falciparum $\lg G$ subclasses and $\lg E$ antibodies levels and the alteration of malaria severity in complicated and uncomplicated malaria patients with or without previous malaria experiences.
\end{abstract}

Methods: Anti-P.falciparum lgG subclasses and IgE antibodies in plasma of complicated and uncomplicated malaria patients with or without previous malaria experiences were analysed using ELISA. IL4-590 polymorphisms were genotyped using RFLP-PCR. Statistical analyses of the lgG subclass levels were done by Oneway ANOVA. Genotype differences were tested by Chi-squared test.

Results: The IL4-590T allele was significantly associated with anti-P. falciparum IgG3 antibody levels in patients with complicated $(P=0.03 \mathrm{I})$, but not with uncomplicated malaria $(P=0.622)$. Complicated malaria patients with previous malaria experiences carrying IL4-590TT genotype had significantly lower levels of anti-P. falciparum $\lg 33(P=0.0156)$, while uncomplicated malaria patients with previous malaria experiences carrying the same genotype had significantly higher levels $(P=0.0206)$ compared to their IL4590 counterparts. The different anti-P. falciparum IgGI and IgG3 levels among IL4 genotypes were observed. Complicated malaria patients with previous malaria experiences tended to have lower lgG3 levels in individuals carrying TT when compared to CT genotypes $(P=0.075)$. In contrast, complicated malaria patients without previous malaria experiences carrying $C C$ genotype had significantly higher anti$P$. falciparum $\lg \mathrm{gI}$ than those carrying either $C T$ or TT genotypes $(P=0.004, P=0.002$, respectively).

Conclusion: The results suggest that IL4-590C or T alleles participated differently in the regulation of anti-malarial antibody isotype profiles in primary and secondary malaria infection and, therefore, could play an important role in alteration of malaria severity. 


\section{Background}

Anti-Plasmodium falciparum specific antibodies play a critical role in immune protection against asexual blood stages of the parasite, in which anti-P. falciparum IgG antibodies involved in reducing severity of the disease [1]. In particular, the cytophilic IgG1 and IgG3 subclasses are considered to protect against $P$. falciparum, whereas IgG2 and IgM are not, and even suggested to block protective effects of the former Ig subclasses [2]. Anti-P. falciparum IgE, as well as total IgE antibodies, which are elevated in individuals exposed to malaria in Thailand, have been implicated to play a pathogenic role during malaria infection [1]. In contrast, the anti-P. falciparum IgE levels in asymptomatic individuals in Tanzania were associated with a reduced risk for subsequent malaria disease [3].

The regulation of antibody profiles in patients with complicated and uncomplicated malaria is still largely unknown. In both human and mice, different cytokines are thought to induce particular Ig isotypes. In humans, IL4 regulates B cells to express the $\gamma 1, \gamma 2, \gamma 3, \gamma 4, \alpha 1, \alpha 2$ and $\varepsilon$, germline gene transcripts (GLT) and to secrete the corresponding proteins [4-6]. IL10 promotes isotype switching from IgM to IgG1, IgG3, IgG4 and/or IgE [7-9] while IFN- $\gamma$ promotes IgG2 $[10,11]$. The inter-individual variation in cytokine production may be reflected by polymorphisms in regulatory region of the corresponding genes. The IL4-590 C/T transition in IL4 promoter was shown to influence the IL4 production as well as the elevated levels of total IgE $[12,13]$. The IL4-590T allele corresponded to IL4-524T and IL4-589T alleles in an alternative numbering scheme [14-16]. In the Fulani tribe in West Africa, IL4$524 \mathrm{~T}$ allele was found to be associated with the elevated levels of anti-P. falciparum IgG antibodies and protection against malaria [14], while IL4-589T allele was associated with the elevated levels of total IgE in children with severe malaria living in Burkina Faso [15]. Conversely, total IgE levels were significantly elevated in children with cerebral malaria who carried IL4-590T allele and have been living in Ghana [16]. Thus, the role of IL4-590T allele in regulating antibody profiles and malaria severity is controversial. In mice infected with Plasmodium chabaudi chabaudi, the specific IgG2a and IgG3 antibodies are predominant in primary polyclonal B cell activation. At that point, IFN- $\gamma$ is markedly stimulated, while IL4 is moderately enhanced. In secondary IgG1-restricted response, only IL4 is produced [17]. According to previous findings, the IL4-590 $\mathrm{C} / \mathrm{T}$ polymorphism influences the balance between IL4 and IFN- $\gamma$ and thus, could alter the severity of malaria [18]. When the same sets of sera were used subsequently to determine the anti-P. falciparum IgG subclasses and IgE antibodies, the results showed different regulation in patients with complicated and uncomplicated malaria [19].
Therefore, it is of interest to evaluate the impact of IL4-590 $\mathrm{C} / \mathrm{T}$ single nucleotide polymorphism (SNP) on the production of anti-P. falciparum -IgG1, -IgG2, -IgG3, IgE antibodies and to determine whether such polymorphism and specific antibodies levels were associated with previous malaria experiences and clinical outcome of the disease in people living in a malaria endemic areas in Thailand.

\section{Methods \\ Malaria subjects}

The same sets of patients previously reported were studied $[18,19]$. Briefly, 110 and 169 patients with complicated (CM) and uncomplicated malaria (UCM), respectively, who had been living at Thai-Myanmar border in the west and Thai-Cambodia border in the east of Thailand; where malaria is endemic; were enrolled. These areas are considered as having low and seasonal malaria transmission. The annual malaria incidence rates in 2001 were 2 to $6 /$ 1,000 population [20]. The two groups of patients were matched for age $(P=0.849)$, gender $(P=0.137)$ and nationality, i.e Thai, Burmese, Mon and Karen $(P=$ 0.614 ). The median age was 25 years (ranged 14-67) for complicated and 24 years (ranged 13-65) for uncomplicated malaria. Based on the interview and clinical records, $27.3 \%$ of patients with complicated and $55 \%$ of those with uncomplicated malaria had previous malaria experiences. The number of previous malaria episodes in these patients varied widely, describing mostly 1-2 episodes of malaria (84/125), 3-8 episodes (27/125) and many episodes (12/125). However, the duration of malaria infection upon admission and the previous malaria episodes among patients were far different, varying from one month to more than 10 years (mostly between one month and two years). However, both groups of patients had acute malaria infection upon admission. Therefore, complicated malaria patients with or without previous malaria experiences (CME, CMN, respectively) and uncomplicated malaria patients with or without previous malaria experiences (UCME, UCMN, respectively) were identified. Clinical manifestations of complicated and uncomplicated malaria were defined according to World Health Organization criteria [21]. Cerebral malaria was defined as unrousable coma with positive asexual forms of $P$. falciparum in blood smears, while other causes of coma were excluded. Severe malaria but not cerebral (non-cerebral severe malaria) was defined as patients exhibiting one or more of the following signs, hyperparasitaemia $(>250,000$ parasite/ml), hypoglycaemia (glucose $<22$ $\mathrm{nmol} / \mathrm{l}$ ), severe anaemia (haematocrit $<20 \%$ or haemoglobin $<7.0 \mathrm{~g} / \mathrm{d}$ ) or increased serum level of creatinine more than $3.0 \mathrm{mg} / \mathrm{dl}$. The patients with complicated malaria comprised of all severe forms including cerebral malaria. Uncomplicated malaria was characterized by a positive blood smear and fever without other causes of 
infections and no manifestations of severe malaria as described. The patients were transported for admission to the Hospital for Tropical Diseases, Faculty of Tropical Medicine, Mahidol University, Bangkok. The study has been ethically approved by the Institute Review Board of the Faculty of Tropical Medicine, Mahidol University, Bangkok and the fully informed consent was obtained from all patients. Other details about the patients are delineated in Table 1.

\section{Blood samples}

Blood samples from patients with complicated and uncomplicated malaria were collected in EDTA sterile tubes before treatment on admission. The plasma and packed cells were separated and frozen at $-20^{\circ} \mathrm{C}$ until use.

\section{Microscopic examination}

Thick and thin films were made for microscopic examination after standard Giemsa staining. Parasite densities were determined by calculating $P$. falciparum parasites per $\mathrm{ml}$ of blood obtained from the number of parasites observed per 1,000 erythrocytes in thin film or per 200 leucocytes in thick film.

\section{Malaria antigens}

The laboratory P. falciparum strain F32 was used to prepare the antigens for malaria antibodies detection. The late stages of $P$. falciparum infected erythrocytes were enriched by $60 \%$ Percoll and sonicated as described [22].

\section{Detection of anti-P. falciparum IgG subclasses and IgE antibody levels}

Anti-P. falciparum -IgG1, -IgG2, -IgG3 and IgE antibodies levels were determined by enzyme-linked immunosorbent assay (ELISA) as described previously [23] with some modification. The monoclonal antibodies used in the ELISA were given [19]. Negative control sera were from Swedish donors who have never been exposed to malaria.

\section{Genotyping}

DNA was extracted from buffy coats by phenol-chloroform extraction [24]. Genomic DNA was used as a template for amplification by PCR and IL4-590 C/T polymorphism was detected by restriction fragment length polymorphism analysis as previously described [18].

\section{Statistical analyses}

The data were analysed using SPSS or StatView computer software. The differences in characteristics of the patients with complicated and uncomplicated malaria were analyzed by unpaired $t$-test or Mann Whitney $U$ test. The highest fever, haemoglobin, creatinine, and glucose levels between the two patient groups were tested by unpaired $t$ test, while the other characteristics were tested by Mann
Whitney $U$ test. The Chi-squared test was used to compare allele and genotype frequencies between the two patients groups. One-way ANOVA and unpaired $t$-test after log transformation were used to evaluate the significant associations between anti-P. falciparum IgG subclasses or IgE antibodies and the IL4-590 genotypes. The IgG subclasses and IgE were taken in the extreme 3 tiles. The genetic distribution of the IL4-590 genotypes between the low and high quartile was compared using Chi-squared test. A Pvalue of less than 0.05 was considered to be significant.

\section{Results}

IL4-590 C/T allele frequency in complicated and uncomplicated malaria patients with or without previous malaria experiences

As described previously [19], the frequency of IL4-590 T allele in patients with complicated malaria did not differ from those with uncomplicated malaria $(0.72$ in both groups). When the allele and genotype frequencies in patients with or without previous malaria experiences were explored, the allele and genotype frequencies between complicated and uncomplicated malaria groups either with or without previous malaria experiences did not differed ( $P$-value allele: 0.7501 vs 0.8755 and genotype: 0.9137 vs 0.9459 for patients with or without previous malaria experiences, respectively) (Table 2)

\section{Association between IL4-590 polymorphism and anti-P. falciparum IgG subclasses and IgE antibody levels}

The anti -P. falciparum -IgG1, -IgG2, -IgG3 and IgE antibody concentrations in relation to IL4-590 genotypes in complicated malaria (CM) and uncomplicated malaria (UCM) patients are illustrated in Table 3. In complicated malaria, the levels of anti-P. falciparum IgG3 were significantly different among individuals carrying IL4-590 TT, CT and CC genotypes $(P=0.031)$, while the levels of anti$P$. falciparum IgG1 tended to be significant among IL4-590 genotype $(P=0.095)$. To study the impact between IL4590 genotypes on anti-P. falciparum IgG1 and IgG3 levels, the antibody levels in individuals carrying different genotypes were compared by TT to CT, TT to CC and CT to CC genotypes. As shown in Table 4, the anti-P. falciparum IgG1 levels were significantly different between individuals carrying TT genotype compared to those carrying CC genotype (median 18.04 vs 223.80: $P=0.025$ ) and between individuals carrying CT genotype compared to those carrying CC genotype (median 24.12 vs 223.80, $P=$ $0.037)$. In contrast, the anti-P.falciparum IgG3 levels were significantly different only between individuals carrying TT compared to those carrying CT genotype (median 0.51 vs $1.20, P=0.030)$. When complicated malaria patients with or without previous malaria experiences (CME and $\mathrm{CMN}$, respectively) were analysed separately, similar patterns were seen by the anti-P. falciparum IgG1 levels were significantly different between individuals carrying TT 
Table I: Characteristics of complicated and uncomplicated malaria patients

\begin{tabular}{|c|c|c|c|}
\hline Characteristics & $\begin{array}{l}\text { Complicated } \\
\text { malaria }(1 / 0)^{a}\end{array}$ & $\begin{array}{l}\text { Uncomplicated } \\
\text { malaria }(169)^{\mathrm{a}}\end{array}$ & $P$-value ${ }^{b}$ \\
\hline $\mathrm{Age}^{\mathrm{c}}$ (range) & $25.0(14-67)$ & $24.0(13-65)$ & 0.849 \\
\hline Sex (male/female) & $75 / 35$ & $133 / 36$ & 0.137 \\
\hline \multicolumn{4}{|l|}{ Nationalityd } \\
\hline Burmese & $17(15.5)$ & $24(14.2)$ & 0.614 \\
\hline Karen & $18(16.4)$ & $27(16.0)$ & \\
\hline Mon & $37(33.6)$ & $72(42.6)$ & \\
\hline Thai & $38(34.5)$ & $45(26.6)$ & \\
\hline Laos & 0 & I (0.6) & \\
\hline \multicolumn{4}{|l|}{ Blood groups } \\
\hline A & $21(19.1)$ & $27(16.0)$ & 0.556 \\
\hline$A B$ & $6(5.5)$ & $7(4.1)$ & \\
\hline B & $34(30.9)$ & $58(34.3)$ & \\
\hline 0 & $47(42.7)$ & $66(39.1)$ & \\
\hline NR & $2(1.8)$ & II (6.5) & \\
\hline \multicolumn{4}{|l|}{ Haemoglobin variants*d } \\
\hline $\mathrm{Hb}$ variants & $14(12.7)$ & $29(17.2)$ & 0.825 \\
\hline Normal & $95(86.4)$ & $133(78.7)$ & \\
\hline NR & I (0.9) & $7(4.1)$ & \\
\hline \multicolumn{4}{|l|}{ G6PD deficiencyd } \\
\hline Deficiency & $13(1 \mid .8)$ & $14(8.3)$ & 0.597 \\
\hline Normal & $96(87.3)$ & $153(90.5)$ & \\
\hline NR & I (0.9) & $2(1.2)$ & \\
\hline Parasitaemia ${ }^{\mathrm{e}}$ (range) & $117322(33-1336900)$ & $564 \mid(17-238800)$ & $<0.0001$ \\
\hline Highest fever ${ }^{\circ} \mathrm{C}^{f}$ & $38.1 \pm 1.005$ & $38.4 \pm 0.981$ & 0.011 \\
\hline Haemoglobin $g / d^{f}$ & $11.4 \pm 0.24$ & $12.1 \pm 0.17$ & 0.021 \\
\hline Creatinine $\mathrm{mg} / \mathrm{dlf}$ & $1.36 \pm 1.21$ & $0.88 \pm 0.37$ & $<0.0001$ \\
\hline Glucose $n m o l / l^{f}$ & $131.47 \pm 62.06$ & $118.17 \pm 28.78$ & 0.016 \\
\hline \multicolumn{4}{|l|}{ Splenomegalyg } \\
\hline Positive & $18(16.4)$ & $3(1.8)$ & 0.039 \\
\hline Negative & $92(83.4)$ & $166(98.2)$ & \\
\hline \multicolumn{4}{|l|}{ Hepatomegalyg } \\
\hline Positive & $66(60)$ & $32(18.9)$ & $<0.0001$ \\
\hline Negative & $44(40)$ & $137(8 \mid .1)$ & \\
\hline \multicolumn{4}{|c|}{ Previous malaria episodes ${ }^{d}$} \\
\hline Yes & $30(27.3)$ & $93(55.0)$ & $<0.0004$ \\
\hline No & $78(70.9)$ & $76(45)$ & \\
\hline NR & $2(1.8)$ & 0 & \\
\hline
\end{tabular}

$\mathrm{a}=$ Number of patients, $\mathrm{b}=$ Mann Whitney $\mathrm{U}$ or unpaired $t$ test used for the analysis, $\mathrm{c}=$ Median, $\mathrm{d}=$ Percentages (in the parenthesis), $\mathrm{e}=$ Geometric mean $/ \mathrm{ml}$ of blood, $f=$ Mean \pm SD, $g=$ Percentages of individual with enlarged spleens and/or liver are in the parenthesis. *The Hemoglobin $(\mathrm{Hb})$ variants includes $\mathrm{HbE}, \mathrm{HbF}$. NR $=$ No report. 
Table 2: Allele and genotype frequencies of IL4-590 polymorphism in complicated and uncomplicated malaria patients with or without previous malaria experiences.

\begin{tabular}{|c|c|c|c|c|c|}
\hline \multirow[t]{2}{*}{ IL4-590 C/T } & \multicolumn{3}{|c|}{ Genotype n (\%) } & \multicolumn{2}{|c|}{ Allele \% } \\
\hline & CC & CT & CC & C & $\mathbf{T}$ \\
\hline CME & $2(7.4)$ & II (40.7) & 14 (5 I.9) & 27.78 & 72.22 \\
\hline UCME & $7(7.7)$ & $33(36.2)$ & $5 I(56.0)$ & 25.82 & 74.18 \\
\hline$P$-value $\#$ & & 0.9137 & & 0.7501 & \\
\hline CMN & $4(5.3)$ & $34(44.7)$ & $38(50.0)$ & 27.63 & 72.37 \\
\hline UCMN & $4(5.4)$ & $35(47.3)$ & 35 (47.3) & 29.05 & 70.95 \\
\hline$P$-value & & 0.9459 & & 0.8755 & \\
\hline
\end{tabular}

\#Chi- squared test was used for the analysis

and CC genotypes (median 8.54 vs 223.80: $P=0.002$ ) as well as between CT and CC genotypes (median 13.94 vs 223.80: $P=0.004$ ). Interestingly, these observations were seen only in complicated malaria patients without previous malaria experiences. While the difference in anti- $P$. falciparum IgG3 levels between patients carrying TT and CT genotype tended to be significant in complicated malaria patients with previous malaria experiences (median 1.32 vs 5.62: $P=0.075$ ). No such tendency could be observed in the levels of anti-P. falciparum IgG2 and IgE in complicated malaria patients either with or without previous malaria experiences. Among uncomplicated malaria patients carrying TT, CT or CC genotypes, the levels of anti-P. falciparum-IgG1, -IgG2, -IgG3 and IgE did not differ.

To investigate whether the anti-P. falciparum IgG subclasses and IgE were associated with certain IL4-590 genotypes and whether the distribution of the $\mathrm{C}$ and/or T allele differed between patients with complicated and uncom- plicated malaria either with low or high specific antibody levels, the antibody profiles were divided into three tiles, i.e. those with low, medium and high antibody levels. This division was based on the findings that there was a great individual variation in antibody responses to the crude plasmodium antigens. Because of the low numbers of homozygotes for the IL4-590 C allele frequency, the individuals homozygous and heterozygous for $\mathrm{C}$ alleles $(\mathrm{CC}+\mathrm{CT})$ were pooled and compared with those homozygous for $\mathrm{T}$ alleles. In complicated malaria, individuals homozygous for $\mathrm{T}$ alleles had significantly lower anti- $P$. falciparum IgG3 antibody $(P=0.0054)$, while no significant difference was found in uncomplicated malaria $(P=0.079)$. Conversely, the IL4-590 genotypes were not significantly associated either with anti-P. falciparum -IgG1, -IgG2 or with anti-P. falciparum IgE antibodies when low and high tiles in complicated and uncomplicated malaria were compared (Table 5). When the results were analysed separately according to the history of individual's malaria experiences, only individuals homozygous for $\mathrm{T}$ alleles had significantly lower anti- $P$. falciparum IgG3 antibody in complicated malaria patients with previous malaria experiences $(\mathrm{CME})(P=0.0156)$ while higher anti-P. falciparum IgG3 antibody levels were seen in uncomplicated malaria patients with previous malaria experiences (UCME) $(P=0.0206)$. In contrast, no such associations could be found when the IL4-590 genotypes were compared between complicated malaria patients without previous malaria experiences $(\mathrm{CMN})$ and uncomplicated malaria patients. Conversely, high anti- $P$. falciparum IgG1 antibody levels seem to be associated with the IL4-590TT genotype in uncomplicated malaria patients with previous malaria experiences (UCME) $(P=$ 0.1219 ) (Table 6). No significant associations between IL4-590 genotypes and anti-P. falciparum IgG2 and IgE antibodies were found when the low and the high tiles

Table 3: Anti-P. falciparum IgG subclass and IgE levels (median) separated by IL4-590 CT genotype in patients with complicated and uncomplicated malaria (CM, UCM).

\begin{tabular}{|c|c|c|c|c|c|c|c|}
\hline & \multicolumn{3}{|c|}{ CC } & \multicolumn{2}{|c|}{ CT } & \multicolumn{2}{|c|}{ TT } \\
\hline & $\mathbf{N}$ & Median & $\mathbf{N}$ & Median & $\mathbf{N}$ & Median & $P$-value \\
\hline \multicolumn{8}{|l|}{ CM } \\
\hline Anti-PflgGI* & 5 & 223.80 & 46 & 24.12 & 53 & 18.04 & 0.096 \\
\hline Anti-PflgG2* & 5 & 6.05 & 46 & 2.03 & 53 & 2.79 & 0.112 \\
\hline Anti-PflgG3* & 5 & 1.51 & 46 & 1.20 & 53 & 1.52 & 0.031 \\
\hline Anti-PflgE** & 5 & 0.43 & 47 & 0.62 & 53 & 2.36 & 0.915 \\
\hline \multicolumn{8}{|l|}{ UCM } \\
\hline Anti-PflgGI* & 11 & 252.80 & 67 & 39.32 & 84 & 88.21 & 0.195 \\
\hline Anti-PflgG2* & 11 & 7.60 & 68 & 4.40 & 83 & 5.77 & 0.299 \\
\hline Anti-PflgG3* & 11 & 2.65 & 68 & 2.69 & 85 & 3.13 & 0.622 \\
\hline Anti-PflgE** & 11 & 0.96 & 68 & 0.65 & 85 & 0.76 & 0.892 \\
\hline
\end{tabular}

$*=\mu g / \mathrm{ml}, * *=\mathrm{ng} / \mathrm{ml}, \mathrm{N}=$ number of patients, \#Statistical analysis of differences

in IgG subclass levels among the different genotypes tested with ANOVA. 
Table 4: Anti-P. falciparum IgGI and IgG3 levels (median) according to IL4-590 genotypes in complicated malaria patients with or without previous malaria experiences.

\begin{tabular}{|c|c|c|c|c|}
\hline & \multicolumn{3}{|c|}{ CM } & \multirow[b]{2}{*}{$P$-value $\#$} \\
\hline & $C C(5)^{a}$ & CT (46) $)^{a}$ & TT (53) & \\
\hline \multirow[t]{3}{*}{ Anti-PflgG I* } & - & 24.12 & 18.04 & 0.628 \\
\hline & 223.80 & - & 18.04 & 0.025 \\
\hline & 223.80 & 24.12 & - & 0.037 \\
\hline \multirow[t]{5}{*}{ Anti-PflgG3* } & - & 1.20 & $0.5 I$ & 0.030 \\
\hline & 1.51 & - & 0.51 & 0.159 \\
\hline & 1.51 & 1.20 & - & 0.455 \\
\hline & & CME & & \\
\hline & CC (2) & CT (II) & TT (I4) & $P$-value \\
\hline \multirow[t]{3}{*}{ Anti-PflgG I* } & - & 31.13 & 53.04 & 0.983 \\
\hline & 280.43 & - & & 0.835 \\
\hline & 280.43 & 31.13 & 53.04 & 0.830 \\
\hline \multirow[t]{5}{*}{ Anti-PflgG3* } & - & 5.62 & 1.32 & 0.075 \\
\hline & 8.06 & - & 1.32 & 0.384 \\
\hline & 8.06 & 5.62 & - & 0.961 \\
\hline & & CMN & & \\
\hline & CC (3) & CT (33) & TT (38) & $P$-value \\
\hline \multirow[t]{3}{*}{ Anti-PflgG I* } & - & 13.94 & 8.54 & 0.636 \\
\hline & 223.80 & - & 8.54 & 0.002 \\
\hline & 223.80 & 13.94 & - & 0.004 \\
\hline \multirow[t]{3}{*}{ Anti-PflgG3* } & - & 0.80 & 0.40 & 0.217 \\
\hline & 1.51 & - & 0.40 & 0.154 \\
\hline & 1.51 & 0.80 & - & 0.274 \\
\hline
\end{tabular}

$*=\mu \mathrm{g} / \mathrm{ml}$, \#Statistical analysis of differences in IgG subclass levels between the different genotypes tested with unpaired $t$-test, $a=$ Number of patients (in the parenthesis).

were compared in all CME, CMN, UCME and UCMN (uncomplicated malaria patients without previous malaria experiences)

\section{Discussion}

This study demonstrated that IL4-590 genotypes could differently regulate anti- $P$. falciparum -IgG1 and -IgG3 responses. The association between individuals homozygous for IL4-590 T alleles and the levels of anti-P. falciparum IgG3 was found only in patients who had previous malaria experiences with low levels in complicated malaria and high levels in uncomplicated malaria. When the differences in antibody levels between genotypes were explored, similar results were seen for anti-P. falciparum IgG3 in that complicated malaria patients with previous malaria experiences tended to have lower IgG3 levels in those carrying TT compared to CT genotypes. In contrast, the complicated malaria patients without previous malaria experiences who carried CC genotype had significantly higher IgG1 than those carrying either CT or TT genotypes. Thus, repeated exposure and host genetics, i.e the polymorphism of IL4-590 or other related genes has an impact on the modulation of antibody isotype profiles and altered clinical outcome.

The relationship between IL4 polymorphism and anti- $P$. falciparum IgG subclasses antibody levels has not been studied thoroughly. This is the first finding to show that a single nucleotide polymorphism at position IL4-590 transition from $\mathrm{C}$ to $\mathrm{T}$ is associated with the levels of anti-P. falciparum IgG3 antibody in malaria patients. In complicated malaria especially those with previous malaria experiences, the levels of anti- $P$. falciparum IgG3 were significantly different among patients carrying IL4-590 CC, CT or TT genotypes. In particular, complicated malaria patients homozygous for IL4-590 $\mathrm{T}$ alleles and with previous malaria experiences exhibited significantly lower levels of anti-P. falciparum IgG3 antibody than their IL4-590 counterparts, whereas significantly higher levels were found in uncomplicated malaria patients homozygous for IL4-590 $\mathrm{T}$ alleles and with previous malaria experiences. Similar trends were observed for the anti-P. falciparum IgG1 in uncomplicated malaria patients with previous malaria experiences although this did not reach statistically significant differences. These results are consistent with the previous findings that low levels of IgG3 may lead to the onset of complicated malaria while high IgG3 antibody levels may protect against malaria $[25,26]$ and with the demonstration on the induction of CD40L stimulated naïve B cells by IL4 alone or in combination with IL10 to express IgG1, IgG2 and IgG3, but little IgG4 [27]. IgG3 can activate the complement pathways [28] and co-operate through FcR receptors [29], thus, IgG3 could induce cell mediated lysis via complement pathways, phagocytosis and/or ADCI mechanism [2,30] which are all known to facilitate parasite clearance. In fact, IgG3 may involve in anti-disease immunity by neutralizing parasite toxin, the glycosylphosphatidylinositol (GPI) membrane anchors of $P$. falciparum surface proteins and/ or inhibiting cytoadherence of infected red blood cells, thus, interfering the parasite sequestration $[31,32]$. In humans, IL10, IL21 are associated with IgG1 and IgG3 antibody production $[7,8,33]$ while IL-27 is modest and regulates exclusively the production of IgG1 [34]. Furthermore, the interaction and combination of different base changes at several sites in the promoter and/or the colocalized alleles of these cytokines and their signaling genes including the IL4-590 polymorphism may differ in patients with complicated and uncomplicated malaria and thus, alter the IgG1 and IgG3 production. This may 
Table 5: Association between IL4-590 genotype and anti-P. falciparum -IgGI, -IgG2, -IgG3 and IgE low or high tiled levels in patients with complicated and uncomplicated malaria.

\begin{tabular}{|c|c|c|c|c|c|c|c|c|c|c|c|}
\hline & \multirow{2}{*}{\multicolumn{2}{|c|}{ 3-tiles of Ig levels }} & \multirow[b]{2}{*}{$\mathbf{N}$} & \multicolumn{3}{|c|}{ Complicated } & \multirow[b]{2}{*}{$P$-value $\#$} & \multicolumn{3}{|c|}{ Uncomplicated } & \multirow[b]{2}{*}{$P$-value } \\
\hline & & & & CC & CT & TT & & CC & CT & TT & \\
\hline Anti-Pf IgGI & & & 274 & $5^{A}$ & $46^{B}$ & $53 \mathrm{C}$ & & $\mathrm{IIA}$ & $67 \mathrm{~B}$ & $84 C$ & \\
\hline Anti-Pf $\lg G 2$ & & & 274 & 5 & 46 & 53 & & II & 68 & 83 & \\
\hline Anti-Pf IgG3 & & & 276 & 5 & 46 & 53 & & 11 & 68 & 85 & \\
\hline Anti-Pf lgE & & & 277 & 5 & 47 & 53 & & 11 & 68 & 85 & \\
\hline \multirow[t]{3}{*}{ Anti-PflgGI* } & Low & $0-14.47$ & $91 \mathrm{D}$ & 0 & 20 & 26 & 0.395 & 2 & 23 & 16 & 0.118 \\
\hline & Medium & $|4.76-106|$. & 92 & 2 & 16 & 16 & & 3 & 20 & 32 & \\
\hline & High & $107.2-1874$ & 91 & 3 & 10 & 11 & & 6 & 24 & 36 & \\
\hline \multirow[t]{3}{*}{ Anti-PflgG2* } & Low & $0.414-2.384$ & 91 & 0 & 26 & 23 & 0.856 & 2 & 23 & 17 & 0.179 \\
\hline & Medium & $2.386-6.617$ & 92 & 3 & 12 & 22 & & 3 & 19 & 29 & \\
\hline & High & $6.629-177$ & 91 & 2 & 8 & 8 & & 6 & 26 & 37 & \\
\hline \multirow[t]{3}{*}{ Anti-PflgG3* } & Low & $0.053-0.798$ & 92 & $\mathbf{I}$ & 19 & 30 & 0.0054 & 3 & 20 & 16 & 0.079 \\
\hline & Medium & $0.854-3.55$ & 92 & 2 & 13 & 18 & & 5 & 22 & 28 & \\
\hline & High & $3.629-119$ & 92 & 2 & 14 & 5 & & 3 & 26 & 41 & \\
\hline \multirow[t]{3}{*}{ Anti-Pf IgE** } & Low & $0.015-0.385 \mid$ & 92 & 2 & 15 & 17 & 0.896 & 3 & 28 & 25 & 0.564 \\
\hline & Medium & $0.3854-1.332$ & 93 & 2 & 17 & 21 & & 4 & 14 & 30 & \\
\hline & High & I.346-29.05 & 92 & 1 & 15 & 15 & & 4 & 26 & 30 & \\
\hline
\end{tabular}

$\mathrm{N}=$ Number of plasma for determining $\lg \mathrm{G} I$, IgG2, $\lg \mathrm{g} 3$, IgE and genotyping IL4-590, \# = Chi-squared test was used to test the difference of IL4$590 \mathrm{CC}+\mathrm{CT}$ and TT distribution between the low and high 3 tiles. $*=\mu \mathrm{g} / \mathrm{ml}$, ** $=\mathrm{ng} / \mathrm{ml}, \mathrm{A}=$ number of patients who carry IL4-590 CC genotype, $B=$ number of patients who carry IL4-590 CT genotype, $C=$ number of patients who carry IL4-590 TT genotype, $D=$ Number of patients who had low, middle and high anti-P. falciparum - $\lg \mathrm{I} I,-\lg \mathrm{g} 2$, - $\lg \mathrm{G} 3$ and $\lg \mathrm{E}$ levels.

also explain why different anti-P. falciparum IgG3 levels were observed only among patients with complicated malaria carrying IL4-590 TT genotype compared to their counterparts.

The present study did not reveal any association between IL4-590 C/T transition and the severity of malaria in either with or without previous malaria experiences, although there was an association between IL4-590 TT genotype and the levels of anti-P. falciparum IgG3 antibody in both complicated and uncomplicated malaria patients with previous malaria experiences. The reason for this discrepancy is probably due to: firstly, the polymorphism itself may not be functional but act as genetic markers of other functional polymorphisms; secondly, the polymorphisms may directly regulate IL4 production only in the presence of other genetic determinants. In contrast to the results recently demonstrated in Mali of West Africa. The IL4-590 $\mathrm{T}$ alleles were associated with the increased levels of both total and anti-malarial IgE in the Fulani, but not the Dogon. However, IL4-590 polymorphism did not influence on the levels of anti-malarial IgG1-3 subclasses in both the Fulani and the Dogon [35]. The reason for genetic disparities can be attributed to different ages, ethnicity, geographical differences, and clinical feature as asymptomatic and acute malaria infection.
The IL4-590 C or T alleles in association with primary and secondary anti-P. falciparum -IgG1 and -IgG3 responses were different. The IL4-590 T allele was associated with anti-P. falciparum IgG3 levels in which the low levels were observed in complicated and the high levels were observed in uncomplicated malaria with previous malaria experiences. In complicated malaria with previous malaria experiences, the anti- $P$. falciparum IgG3 levels tended to be lower in patients carrying TT than those carrying CT genotypes. Conversely, the IL4-590 T allele seems to be associated with high anti-P. falciparum IgG1 in only uncomplicated malaria patients with previous malaria experiences, whereas, complicated malaria patients without previous malaria experiences who carried CC genotype had significantly higher anti- $P$. falciparum IgG1 than those either with CT or TT genotypes. Therefore, it is likely that $\mathrm{T}$ allele associated with secondary malaria infection, while $\mathrm{C}$ allele associated with primary infection. The shift of Ig-isotypes from primary to secondary responses has been demonstrated in mouse models to be correlated with the levels of either Th1 or Th2 cytokines [17]. Th1 subset predominates in the nonspecific primary response, whereas Th2 is the major activated pathway in the secondary specific response. As demonstrate earlier that the nuclear factor of activated $\mathrm{T}$ cells (NFAT) binding site at IL4-590 T creates a hair trigger for 
Table 6: Association between IL4-590 genotype and anti-P. falciparum -IgGI and -IgG3 levels base on previous experiences malaria infection in patients with complicated and uncomplicated malaria.

\begin{tabular}{|c|c|c|c|c|c|c|c|c|c|c|}
\hline & & & \multicolumn{8}{|c|}{ Complicated malaria } \\
\hline & & & \multicolumn{4}{|c|}{ Without previous malaria experiences $(76)^{a}$} & \multicolumn{4}{|c|}{ With previous malaria experiences (27) } \\
\hline & \multicolumn{2}{|c|}{ 3-tiles of Ig levels } & CC & CT & TT & $P$-value $\#$ & CC & CT & TT & $P$-value $\#$ \\
\hline \multirow[t]{3}{*}{ Anti-PflgGI* } & Low & $0-14.47$ & $\mathrm{OA}^{\mathrm{A}}$ & $17 \mathrm{~B}$ & $21 \mathrm{C}$ & 0.1373 & 0 & 3 & 4 & 0.7715 \\
\hline & Medium & $|4.76-106|$. & 1 & 11 & 11 & & 1 & 4 & 5 & \\
\hline & High & $107.2-1874$ & 2 & 5 & 6 & & 1 & 4 & 5 & \\
\hline \multirow[t]{3}{*}{ Anti-PflgG3* } & Low & $0.053-0.798$ & 0 & 17 & 23 & 0.2136 & $\mathbf{I}$ & 2 & 6 & 0.0156 \\
\hline & Medium & $0.854-3.55$ & 2 & 10 & 11 & & 0 & 2 & 7 & \\
\hline & High & $3.629-119$ & 1 & 6 & 4 & & I & 7 & I & \\
\hline
\end{tabular}

Uncomplicated malaria

\begin{tabular}{|c|c|c|c|c|c|c|c|c|c|c|}
\hline & & & \multicolumn{4}{|c|}{ Without previous malaria experiences (74) } & \multicolumn{4}{|c|}{ With previous malaria experiences (91) } \\
\hline & & & CC & CT & TT & $P$-value $\#$ & CC & CT & TT & $P$-value $\#$ \\
\hline \multirow[t]{3}{*}{ Anti-PflgGI } & Low & $0-14.47$ & 0 & 15 & 11 & 0.8019 & 2 & 7 & 5 & 0.1219 \\
\hline & Medium & $|4.76-106|$. & 2 & 9 & 12 & & I & 11 & 20 & \\
\hline & High & $107.2-1874$ & 2 & 11 & 11 & & 4 & 13 & 25 & \\
\hline \multirow{3}{*}{ Anti-PflgG3 } & Low & $0.053-0.798$ & I & 13 & 12 & 0.8772 & 2 & 7 & 4 & 0.0206 \\
\hline & Medium & $0.854-3.55$ & 1 & 10 & 12 & & 4 & II & 16 & \\
\hline & High & $3.629-119$ & 2 & 12 & 11 & & $\mathbf{I}$ & 14 & 30 & \\
\hline
\end{tabular}

$\mathrm{a}=$ Number of patients (in the parenthesis), \# = Chi- squared test was used to test the difference of IL4-590 CC, CT and TT distribution between the low and high 3 tiles, $*=\mu \mathrm{g} / \mathrm{ml}, \mathrm{A}, \mathrm{B}$ and $\mathrm{C}=$ number of patients with previous malaria experiences for determining anti-P. falciparum -lgG,lgG3 and carry IL4-590 CC, CT, TT genotypes, respectively.

IL4 transcription, it is advantageous when a Th2 response is required, while IL4-590 C is favored when a Th1 response is required [36]. Therefore, the modulation of Th1 and Th2 cytokines productions could have the impact on antibody classes and subclasses productions. It is possible that $I L 4-590^{\circ} \mathrm{C}$ or $\mathrm{T}$ in combination with previous exposure to malaria antigens probably partly modify the antibody isotype profiles and thus represent a wide spectrum of clinical symptoms. However, some of these observations need to be confirmed in a larger sample size in order to correct the confounding factors, such as age, number of previous episodes and parasite-virulence.

\section{Conclusion}

This study showed that IL4-590 C or T is likely to play a modulating role in the regulation of antibody profiles in primary and secondary immune responses. The IL4-590 T allele participated in the regulation of anti-P. falciparum IgG1 and -IgG3 in secondary infection, whereas IL4-590 C allele might participated in the regulation of anti-P. falciparum IgG1 in primary infection. In individuals carrying the IL4-590 TT genotype with previous malaria experiences, an increased risk of complicated malaria was asso- ciated with low anti-P. falciparum IgG3 antibody, whereas a lower risk was associated with high antibody levels. However, a panel of genetic variations in humoral immune responses and their related genes in larger sample size should be further investigated which may provide clue for better understanding in the alteration of disease severity.

\section{List of abbreviations used}

CM: complicated malaria patients; CME: complicated malaria patients with previous malaria experiences; $\mathrm{CMN}$ : complicated malaria patients without previous malaria experiences; UCM: uncomplicated malaria patients; UCME: uncomplicated malaria patients with previous malaria experiences; UCMN: uncomplicated malaria patients without previous malaria experiences.

\section{Competing interests}

The authors declare that they have no competing interests.

\section{Authors' contributions}

SK and PT designed the study; PT prepared the blood samples, performed the IL4-590 genotyping and ELISA, col- 
lected clinical data, analysed statistics and drafted the manuscript; HP contributed to ELISA; MH assisted in IL4590 genotyping; SK and MTB supervised the work, revised the manuscript and financed the research. All authors read and approved the final manuscript.

\section{Acknowledgements}

We wish to acknowledge the contribution of Late Professor Sornchai Looareesuwan, Department of Clinical Tropical Medicine and the Hospital for Tropical Diseases, Faculty of Tropical Medicine, Mahidol University in providing blood samples and clinical data and his staff for their assistance in blood collection. We thank all patients for their kind participation in the study and Margareta Hagstedt, Stockholm University for her technical assistance. This study was supported by The Royal Golden Jubilee Ph.D. Programme (5 MMU44A I), the Basic Research Grant for the Royal Golden Jubilee Ph.D. (BGJ4580004) of the Thailand Research Fund (TRF), the Swedish Foundation for International Cooperation in Research and Higher Education (STINT), the Swedish International Development Co-operation Agency (SIDA/SAREC), the BioMalPar EU, \#LSHP-CT-2004, 503578, Faculty of Tropical Medicine, Mahidol University and the Faculty of Medicine, Srinakharinwirot University. The present study was approved by the Ethical Committee of Faculty of Tropical Medicine, Mahidol University.

\section{References}

I. Perlmann P, Perlmann H, Looareesuwan S, Krudsood S, Kano S, Matsumoto Y, Brittenham G, Troye-Blomberg M, Aikawa M: Contrasting functions of IgG and IgE antimalarial antibodies in uncomplicated and severe Plasmodium falciparum malaria. Am J Trop Med Hyg 2000, 62:373-377.

2. Bouharoun-Tayoun H, Druilhe P: Plasmodium falciparum malaria: evidence for an isotype imbalance which may be responsible for delayed acquisition of protective immunity. Infect Immun 1992, 60:1473-1481.

3. Bereczky S, Montgomery SM, Troye-Blomberg M, Rooth I, Shaw MA, Farnert $A$ : Elevated anti-malarial IgE in asymptomatic individuals is associated with reduced risk for subsequent clinical malaria. Int J Parasitol 2004, 34:935-942.

4. Cerutti A, Zan H, Schaffer A, Bergsagel L, Harindranath N, Max EE, Casali P: CD40 ligand and appropriate cytokines induce switching to IgG, IgA, and IgE and coordinated germinal center and plasmacytoid phenotypic differentiation in a human monoclonal IgM+IgD+ B cell line. J Immunol 1998, 160:2145-2157.

5. Cerutti A, Zan H, Kim EC, Shah S, Schattner EJ, Schaffer A, Casali P: Ongoing in vivo immunoglobulin class switch DNA recombination in chronic lymphocytic leukemia B cells. J Immunol 2002, 169:6594-6603.

6. Fear DJ, McCloskey N, O'Connor B, Felsenfeld G, Gould HJ: Transcription of Ig germline genes in single human $B$ cells and the role of cytokines in isotype determination. J Immunol 2004, 173:4529-4538.

7. Malisan F, Briere F, Bridon JM, Harindranath N, Mills FC, Max EE, Banchereau J, Martinez-Valdez H: Interleukin- 10 induces immunoglobulin $G$ isotype switch recombination in human CD40activated naive B lymphocytes. J Exp Med 1996, I 83:937-947.

8. Fujieda S, Saxon A, Zhang K: Direct evidence that gamma $I$ and gamma 3 switching in human B cells is interleukin-10 dependent. Mol Immunol 1996, 33: I335-1343.

9. Jeannin P, Lecoanet S, Delneste Y, Gauchat JF, Bonnefoy JY: IgE versus IgG4 production can be differentially regulated by IL- 10 . J Immunol 1998, 160:3555-356I.

10. Kawano $Y$, Noma T, Yata J: Regulation of human IgG subclass production by cytokines. IFN-gamma and IL-6 act antagonistically in the induction of human IgGI but additively in the induction of IgG2. J Immunol 1994, I 53:4948-4958.

II. Kondo N, Inoue R, Kasahara K, Fukao T, Kaneko H, Tashita H, Teramoto $\mathrm{T}$ : Reduced expression of the interferon-gamma messenger RNA in IgG2 deficiency. Scand J Immunol 1997, 45:227-230.
12. Rosenwasser LJ, Klemm DJ, Dresback JK, Inamura H, Mascali J], Klinnert M, Borish L: Promoter polymorphisms in the chromosome 5 gene cluster in asthma and atopy. Clin Exp Allergy 1995, 25(Suppl 2):74-78. discussion 95-76

13. Nakashima H, Miyake K, Inoue Y, Shimizu S, Akahoshi M, Tanaka Y, Otsuka T, Harada M: Association between IL-4 genotype and IL-4 production in the Japanese population. Genes Immun 2002, 3:107-109.

14. Luoni G, Verra F, Arca B, Sirima BS, Troye-Blomberg M, Coluzzi M, Kwiatkowski D, Modiano D: Antimalarial antibody levels and IL4 polymorphism in the Fulani of West Africa. Genes Immun 200I, 2:4II-4I4

15. Verra F, Luoni G, Calissano C, Troye-Blomberg M, Perlmann P, Perlmann H, Arca B, Sirima BS, Konate A, Coluzzi M, Kwiatkowski D, Modiano D: IL4-589C/T polymorphism and IgE levels in severe malaria. Acta Trop 2004, 90:205-209.

16. Gyan BA, Goka B, Cretkovic JT, Kurtzhals JL, Adabayeri V, Perlmann $\mathrm{H}$, Lefvert AK, Akanmori BD, Troye-Blomberg M: Allelic polymorphisms in the repeat and promoter regions of the interleukin-4 gene and malaria severity in Ghanaian children. Clin Exp Immunol 2004, 138: 145-150.

17. D'Imperio Lima MR, Alvarez JM, Furtado GC, Kipnis TL, Coutinho A, Minoprio P: Ig-isotype patterns of primary and secondary B cell responses to Plasmodium chabaudi chabaudi correlate with IFN-gamma and IL-4 cytokine production with CD45RB expression by CD4+ spleen cells. Scand J Immunol 1996, 43:263-270.

18. Tangteerawatana $P$, Pichyangkul $S$, Hayano $M$, Kalambaheti $T$, Looareesuwan S, Troye-Blomberg M, Khusmith S: Relative levels of IL4 and IFN-gamma in complicated malaria: association with IL4 polymorphism and peripheral parasitemia. Acta Trop 2007, 101:258-265.

19. Tangteerawatana P, Montgomery SM, PerImann H, Looareesuwan S, Troye-Blomberg M, Khusmith S: Differential regulation of IgG subclasses and IgE antimalarial antibody responses in complicated and uncomplicated Plasmodium falciparum malaria. Parasite Immunol 2007, 29:475-483.

20. Singhasivanon P, Kidson C, Supavej S, eds: Mekong Malaria II: update of malaria, multi-drug resistance and economic development in the Mekong region of Southeast Asia. Southeast Asia J Trop Med and Pub Health 2003, 34(suppl 4):63-68.

21. World Health Organization: Severe and complicated malaria. Trans R Soc Trop Med Hyg 2000, 94(Suppl):5I-90.

22. Troye-Blomberg M, Perlmann H, Patarroyo M, Perlmann P: Regulation of the immune response in Plasmodium falciparum malaria. II. Antigen specific proliferative responses in vitro. Clin Exp Immunol 1983, 53:345-353.

23. Perlmann H, Helmby H, Hagstedt M, Carlson J, Larsson P, TroyeBlomberg M, Perlmann P: IgE anti-malarial antibodies in Plasmodium falciparum malaria: association of high IgE levels with cerebral malaria. Clin Exp Immunol 1994, 97:284-292.

24. Alloueche A, Silveira H, Conway DJ, Bojang K, Doherty T, Cohen J, Pinder M, Greenwood BM: High-throughput sequence typing of T-cell epitope polymorphisms in Plasmodium falciparum circumsporozoite protein. Mol Biochem Parasitol 2000, 106:273-282.

25. Metzger WG, Okenu DM, Cavanagh DR, Robinson JV, Bojang KA, Weiss HA, McBride JS, Greenwood BM, Conway DJ: Serum IgG3 to the Plasmodium falciparum merozoite surface protein 2 is strongly associated with a reduced prospective risk of malaria. Parasite Immunol 2003, 25:307-3I2.

26. Sarthou JL, Angel G, Aribot G, Rogier C, Dieye A, Toure Balde A, Diatta B, Seignot P, Roussilhon C: Prognostic value of anti-Plasmodium falciparum-specific immunoglobulin $G 3$, cytokines, and their soluble receptors in West African patients with severe malaria. Infect Immun 1997, 65:327I-3276.

27. Tangye SG, Ferguson A, Avery DT, Ma CS, Hodgkin PD: Isotype switching by human $B$ cells is division-associated and regulated by cytokines. J Immunol 2002, 169:4298-4306.

28. Burton DR, Gregory L, Jefferis R: Aspects of the molecular structure of IgG subclasses. Monogr Allergy 1986, 19:7-35.

29. Groux H, Gysin J: Opsonization as an effector mechanism in human protection against asexual blood stages of Plasmodium falciparum: functional role of IgG subclasses. Res Immunol 1990, 141:529-542.

30. Tebo AE, Kremsner PG, Luty AJ: Plasmodium falciparum: a major role for IgG3 in antibody-dependent monocyte-mediated 
cellular inhibition of parasite growth in vitro. Exp Parasitol 200I, 98:20-28.

31. Boutlis CS, Fagan PK, Gowda DC, Lagog M, Mgone CS, Bockarie MJ, Anstey NM: Immunoglobulin G (IgG) responses to Plasmodium falciparum glycosylphosphatidylinositols are short-lived and predominantly of the IgG3 subclass. J Infect Dis 2003, 187:862-865.

32. Schofield L, Mueller I: Clinical immunity to malaria. Curr Mol Med 2006, 6:205-22I.

33. Mewono L, Matondo Maya DW, Matsiegui PB, Agnandji ST, Kendjo E, Barondi F, Issifou S, Kremsner PG, Mavoungou E: Interleukin-2I is associated with IgGI and IgG3 antibodies to erythrocytebinding antigen- 175 peptide 4 of Plasmodium falciparum in Gabonese children with acute falciparum malaria. Eur Cytokine Netw 2008, 19:30-36.

34. Boumendjel A, Tawk L, Malefijt RW, Boulay V, Yssel H, Pene J: IL-27 induces the production of IgG I by human B cells. Eur Cytokine Netw 2006, 17:28I-289.

35. Vafa M, Maiga B, Israelsson E, Dolo A, Doumbo OK, Troye-Blomberg M: Impact of the IL-4 -590 C/T transition on the levels of Plasmodium falciparum specific IgE, IgG, IgG subclasses and total IgE in two sympatric ethnic groups living in Mali. Microbes Infect 2009, I I:779-784.

36. Rockman MV, Hahn MW, Soranzo N, Goldstein DB, Wray GA: Positive selection on a human- specific transcription factor binding site regulating IL4 expression. Curr Biol 2003, 13:2 I I 8-2 I 23.

Publish with BiolMed Central and every scientist can read your work free of charge

"BioMed Central will be the most significant development for disseminating the results of biomedical research in our lifetime. "

Sir Paul Nurse, Cancer Research UK

Your research papers will be:

- available free of charge to the entire biomedical community

- peer reviewed and published immediately upon acceptance

- cited in PubMed and archived on PubMed Central

- yours - you keep the copyright

Submit your manuscript here:

http://www.biomedcentral.com/info/publishing_adv.asp
BiolMedcentral 